${ }^{20}$ Yamatot T, Yokota T. Beta-lactamase-directed barrier for penicillins of Escherichia coli carrying $\mathrm{R}$ plasmids. Antimicrob Agents Chemother 1977;11:936-40.

21 Then RL, Angehrn P. Trapping of nonhydrolyzable cephalosporins by cephalosporinases in Enterobacter cloacae and Pseudomonas aeruginosa. Antimicrob Agents Chemother 1982;21:711-7.

${ }^{22}$ Sanders CC. Novel resistance selected by the new expanded-spectrum cephalosporins: a concern. F Infect Dis 1983;147:585-9.

${ }^{23}$ Minami S, Yotsuji A, Inoue $M$, Mitsuhashi S. Induction of $\beta$-lactamase by various $\beta$-lactam antibiotics in Enterobacter cloacae. Antimicrob Agents Chemother 1980;18:382-5.

${ }^{24}$ Preheim LC, Penn RG, Sanders CC, Goering RV, Giger DK. Emergence of resistance to $B$-lactam and aminoglycoside antibiotics during moxalactam therapy of Pseudomonas aeruginosa infections. Antimicrob Agents Chemother 1982;22:1037-41.

${ }^{25}$ Murray PR, Granich GG, Krogstad DJ, Niles AC. In vivo selection of resistance to multiple cephalosporins by Enterobacter cloacae. $\mathcal{F}$ Infect Dis $1983 ; 147 \cdot 590$.

${ }^{26}$ Sanders CC, Moellering RC, Martin RR, et al. Resistance to cefamandole: a collaborative study of emerging clinical problems. F Infect Dis 1982; 145:118-25.

27 Goering RV, Sanders CC, Sanders WE Jr. Antagonism of carbenicillin and cefamandole by cefoxitin in treatment of experimental infections in mice. Antimicrob Agents Chemother 1982;21:963-7.

28 The EORTC International Antimicrobial Therapy Project Group. Three antibiotic regimens in the treatment of infection in febrile granulocytopenic patients with cancer. $\mathcal{F}$ Infect Dis $1978 ; 137: 14-29$.

${ }^{29}$ Klastersky J, Hensgens C, Debusscher L. Empiric therapy for cancer patients: comparative study of ticarcillin-tobramycin, ticarcillincephalothin, and cephalothin-tobramycin. Antimicrob Agents Chemother $1975 ; 7: 640-5$.

${ }^{30}$ Bodey GP, Ketchel SJ, Rodriguez V. A randomized study of carbenicillin plus cefamandole or tobramycin in the treatment of febrile episodes in cancer patients. Am 7 Med 1979;67:608-16.

\section{Self help}

\begin{abstract}
"One of my clients has a daughter with Pierre Robin's syndrome and would like to be put in contact with other parents in similar circumstances"-letter in "Health Visitors' Association fournal'1
\end{abstract}

Over half a million self help groups are said to exist in the United States, ${ }^{2}$ and when the Sunday Times published its first edition of the Self Help Directory in 1975 it sold out and has since run to three editions. ${ }^{3}$ The recently founded College of Health offers to its subscribers "information services on self help groups," as well as other benefits for the $£ 10$ membership, and the 1983 GP Guide includes 17 pages of addresses of self help organisations for family doctors' reference. ${ }^{4}$ The monthly Mother and Baby Magazine regularly publishes a page of 62 addresses to which its readers can apply for help and support (from the Association for Improvement of Maternity Services to the Vegetarian Society of the United Kingdom) and the agony aunts of the popular women's magazines are thought to deal with 10000 letters a week from readers who want more information about their illnesses and treatment. ${ }^{5}$

Clearly the public has a vast appetite for information about illness. The conclusion must be that because we live in a literate society communication by the written word is ever more necessary to supplement what has been said by word of mouth: the doctor's consultation alone is not enough. Doctor-patient contacts may be too brief to satisfy all the questions that need answering, patients may want to feel self reliant, ${ }^{6}$ have a second opinion, ${ }^{5}$ solve a common problem through mutual aid, ${ }^{6}$ or exchange information and support to alleviate feelings of isolation brought about by illness or disaster in the family. These are not unreasonable aspirations.

Can a family doctor who has not actually had a diabetic child in his own family understand and anticipate all the day to day problems of management that the diagnosis will bring to the parents? Or can he provide lifelong emotional support for the parents of a baby with Down's syndrome? Or can he cope from personal experience with the ever recurrent problems of the alcoholic, the gambler, the paraplegic, or patients with multiple sclerosis, mastectomy, or eczema? The general practitioner may well be the constant provider of primary medical care, but in contemporary society he can be neither omniscient nor omnipotent with regard to all its ills.

For many people a self help organisation may offer a special lifeline, a companion, comfort, a source of practical help, and an easing of the burden that is not provided by any other source of medical or social care. ${ }^{6}$ It may provide people with their only opportunity to stand on their own feet and be independent from what they see as stigmatising help from the many arms of the welfare state. ${ }^{6}$ This sort of help may be seen as a "welcome alternative to the expensive services of paid professionals" if it provides effective support for those with particular socioeconomic problems-the single parent, the carer for elderly relatives, the homeless, and the relatives of patients with physical and mental handicaps. ${ }^{6}$

Organisations of this kind are developing rapidly-and not on the initiative of the medical professions. One recent survey showed that only $18 \%$ of the people concerned had heard of their self help organisation through their doctor or health visitor; most had learnt of the help available through word of mouth, newspaper, magazine, statutory organisation, or the Citizen's Advice Bureau. ${ }^{6}$

Most, if not all, mutual aid organisations and most local groups provide a similar range of activities for their members: leaflets, booklets, magazines, newsletters, and reading lists, meetings and social occasions-all of which help to provide mutual support and exchange of information. Direct services may be available to help with practical problems. Some organisations collect funds for research, while others are active in political work to improve statutory services and stimulate the greater understanding of members' needs. ${ }^{6}$

Mutual aid organisations need be neither feared nor viewed with suspicion by the medical establishment-indeed, without their help many of our patients would be the poorer served and medical as well as social research much less well endowed. Many local authorities employ community workers to liaise with and advise local voluntary organisations. Experienced health visitors and medical social workers build up contacts with those organisations that have provided effective help. The British Red Cross Society, the Citizen's Advice Bureau, and the Women's Royal Voluntary Service may all refer requests for help to the appropriate self help organisation. From Action Against Allergy to Women's National Cancer Control Campaign and from Age Concern to Women's Aid, the alphabetical lists available in the various directories encompass diseases and disorders from asthma to thalassaemia and from anorexia to tetraplegia. ${ }^{3}{ }^{7-14}$ Their leaflets are obtainable for the surgery or outpatient waiting area display, their staff are often of inestimable help to our patients, and their services, information, guidance, and support are an essential complement to what the doctor can provide.

\section{Alexander D G GunN}

Director,

University Health Service,

Reading RG2 7HE

${ }^{1}$ Anonymous. Health Visitors' Association fournal 1983;56:14.

2 Whitehorne K. Your life in your hands. Observer 1983 Nov 13:25 (cols 1-6), 26 (cols 1-7). 
${ }^{3}$ Gillie O, Chisholm J. The "Sunday Times" self-help directory. London Times Newspapers, 1976.

+ Gee JL, Gee RC. 1983 GP guide. Petersfield: Asgard Publishing Co, 1983

5 Smith R. Part time agony aunt in trousers. Br Med f 1983;287:1029-32.

${ }^{6}$ Richardson A, Goodman M. Self-help and social care: mutual aid organisations in practice. London: Policy Studies Institute, 1983.

${ }^{7}$ Guardian. Directory of pressure groups and representative organisations. Epsom: Bowker Publications, 1979.

${ }^{*}$ Knight S. Help! I need somebody. A guide to national associations for people in need. 3rd ed. London: Henry Kimpton, 1980.

${ }^{9}$ Moorehead C. Helping, a guide to voluntary work. London: Macdonald and Janes, 1975.

1" Patients' Association. Self help and the patient. London: Patients' Association, 1982.

"Share Community. Guide to self-help groups. London: Share Community Ltd, 1980.

12 Thames Television. Health help. London: Thames Television, 1978.

13 Todd J. Someone to talk to. Directory of self-help and support services. London: Mental Health Foundation, 1982.

${ }^{14}$ Gillie O, Price A, Robinson S. Sunday Times self-help directory. London : Granada; 1982.

\section{What carbohydrate foods should diabetics eat?}

Before the days of insulin and oral hypoglycaemic agents little could be offered to diabetic patients other than dietary advice. Drug treatment heralded an era of diminishing enthusiasm for the role of diet in the management of diabetes-to the extent that in the early 1970s standard medical textbooks devoted no more than a few paragraphs to $\operatorname{diet}^{1}$ and many hospitals did not have a dietitian to advise diabetic patients. Around that time West reviewed the attitudes of diabetic patients in North America towards the dietary advice they had been given. ${ }^{2}$ Some $22 \%$ claimed not to have received any advice, and $25 \%$ said that they had received some advice but had made no attempt to follow it. Only about half of all American diabetics claimed to be following a prescribed diet, and much the same was true in Britain. ${ }^{3}$

During the mid- to late 1970s attitudes began to change. Epidemiological evidence suggested that the standard diabetic diet, low in carbohydrate and relatively high in fat, might actually increase the risk of cardiovascular disease, the most frequent cause of death among diabetics. ${ }^{4}$ Furthermore, several studies suggested that diets relatively high in fibre rich carbohydrate reduced hyperglycaemia in diabetic patients. ${ }^{5-8}$ Though there remains some disagreement about the precise quantity of carbohydrate which should be included in the diabetic diet, ${ }^{9}$ the diabetic associations of many Western countries, including the United States, ${ }^{10}$ Britain, ${ }^{11}$ Canada, ${ }^{12}$ Australia, ${ }^{13}$ and Finland, ${ }^{14}$ have affirmed the importance of diet in the management of diabetes and recommended an increase in unrefined carbohydrate (especially fibre rich carbohydrate) with a reduction in the fat intake. Nevertheless, restriction of monosaccharides and disaccharides remains a cornerstone of diabetic dietary policy and clear advice is needed on which carbohydrate foods are the most suitable for diabetic patients.

Two approaches may be used to answer this question: short term experiments examining the response of the blood glucose concentration to various foods and longer term studies. Most investigators have used the first approach. The greatest number of foods has been studied by Jenkins and his colleagues, ${ }^{15}$ who are particularly well known for their work showing the reduction of postprandial glycaemia by the gel forming fibre guar. ${ }^{16}$ In a comparison of 15 carbohydrate containing foods they found that dried leguminous seeds-for example, kidney beans, red lentils, black eyed peas, and chick peas-produced a glycaemic response substantially lower (44\% to $71 \%$ ) than that of wholemeal bread. These findings are not surprising since longer term studies have shown a substantial improvement in diabetic control when gel forming fibres from such leguminous sources have been added to the diabetic diet in substantial quantities. ${ }^{2}$ Glycaemic responses for rice, spaghetti, and All Bran were in an intermediate category, being higher than those for beans but below those for bread. Surprisingly there was no difference between white and wholemeal bread. In these circumstances All Bran appeared to be a relatively "good" food despite the fact that one third of its total carbohydrate is made up of disaccharides.

The work of Crapo and her colleagues has aroused interest because they found that potato has a glycaemic response similar to that of dextrose-both worse than bread; white rice and corn were better than bread. ${ }^{17}$ In the light of these observations and others in non-diabetics ${ }^{18} 19$ the recent report by Bantle and coworkers should not have caused much surprise. ${ }^{20}$ In a well conducted study they found that sucrose, fed as part of a mixed meal, did not produce higher plasma glucose concentrations than when carbohydrate was derived chiefly from the unrefined sources of potato and wheat. Meals containing fructose resulted in lower glycaemic excursions.

Nevertheless, taken together these studies raise some questions concerning two fundamental aspects of the new dietary recommendations. Firstly, are all starchy carbohydrate foods rich in dietary fibre suitable for diabetics? Secondly, is restriction of sugar really of crucial importance?

On the first issue undoubtedly foods rich in gel forming fibre (found particularly in various types of cooked dried beans) are especially useful in the diabetic diet. The results of long term studies ${ }^{7}$ have confirmed those of the shorter experiments. ${ }^{15}$ Furthermore, these foods provide a useful source of protein, allowing the diet to contain less animal protein, which is so often high in saturated fat, and they also lower serum cholesterol concentrations. ${ }^{21}$ The main reason for this beneficial effect of beans compared with all other carbohydrate foods seems to be delayed digestion. ${ }^{15}$ Malabsorption of carbohydrate may occur, but not to any great extent, and it does not appear to produce any long term problems. ${ }^{22}$

Advice about other starchy carbohydrate foods is, however, less clear cut. The results of test meal studies suggest that the amount of dietary fibre is not the only determinant of the glycaemic response: the response to wholemeal (high fibre) and white (low fibre) bread is the same, ${ }^{15}$ and wheat in pasta elicits a lower response than wheat in bread. ${ }^{23}$ Whole rice also results in a much flatter blood glucose curve than rice flour, ${ }^{24}$ and glucose and insulin responses to whole apples or apples as purée differ, ${ }^{25}$ which suggests that particle size and integrity of structure may be important. The results of laboratory studies of digestion with human digestive enzymes show that the rate of starch hydrolysis correlates well with the biological response to ingested food, ${ }^{24}$ and such techniques might therefore be used to predict physiological response to food..$^{26}$ Does this mean that wholemeal bread and potato (already identified according to their glycaemic responses as less satisfactory than several other foods in the test meal experiment) should be eliminated from or at least discouraged in the diabetic diet, or that suitability of foods for the diabetic may in future be determined in the laboratory?

The answer to both questions must be no, at least in the light of present knowledge. Wholemeal bread and potatoes have formed a substantial part of several experimental diets which have over weeks or months shown an appreciable improvement in diabetic control. ${ }^{27} 28$ Furthermore, a recent 